\title{
A review of Solvency II: has it met its objectives?
}

\section{Abstract of the London Discussion}

[Institute and Faculty of Actuaries Sessional Research Event London, 11 September 2017]

This abstract relates to the following paper: Rae, R.A., Barrett, A., Brooks, D., Chotai, M.A., Pelkiewicz, A.J. and Wang, C. A review of Solvency II: has it met its objectives? British Actuarial Journal. doi: 10.1017/S1357321717000241

The Chairman (Mr S. W. Dixon, F.I.A.): Welcome to tonight's discussion: “A review of Solvency II: has it met its objectives?” presented by the Retrospective on Solvency II Working Party.

What can I say as an introduction to this topic? For an actuary working with the net premium valuation method at with-profits insurers, the change to the realistic balance sheet has been fundamental. Boards have come a long way in the past three or four years and actuarial techniques have had to be rethought from scratch. Risk management is now fundamental to the job.

Now I should like to introduce our opener for this evening, Paul Fulcher. Paul is the head of AssetLiability Management (ALM) structuring for Nomura International Plc, responsible for providing Solvency II solutions to clients. In his professional capacity, he chairs the Life Research Committee. $\mathrm{He}$ is also a member of the Life Board.

Mr P. Fulcher, F.I.A. (opening the discussion): On behalf of the Life Research Committee, I would like to thank the Retrospective on Solvency II Working Party for an important and timely paper, particularly the European Insurance and Occupational Pensions Authority (EIOPA) review of Solvency II and the Treasury Select Committee enquiry - both of which the Working Party will update us on later.

I thought it would be worth reminding ourselves how badly timed Solvency II was. Solvency II was designed in the Goldilocks economy, the NICE (non-inflationary consistent expansionary) world, where things were not volatile. The final version of Solvency II, or what was supposed to be the final version, was adopted on 10 July 2007. It came with a report from the European Central Bank saying it would have no impact on markets. A proud boast. It was based on sound economic valuation principles, market prices and a glowing report from the industry. Very few issues were raised.

Thirty days later, on 9 August 2007, BNP Paribas suspended redemptions on some of their assetbacked security funds.

What was the reason for doing that? It was impossible to value certain assets. In other words, 30 days after Solvency II started, based on market consistent valuation, we had a global crisis because we did not really trust market prices any more. 
The subsequent market turbulence arguably called market-consistent valuation, the foundation of Solvency II, into question. It also flushed out a whole load of other risks in the financial services system we had not thought about before. Certainly, as someone who works for a bank rather than an insurer, our rulebook was torn up and thrown out of the window, and we started again. Maybe we should have done that with Solvency II, but we did not. With Solvency II, we had what was called the long-term guarantees package, which was a rather interesting political compromise. All sorts of national fixes - something for the Italians, something for the German industry, a bit for the Spanish and quite a lot for the UK - were designed to get us back to the answer that we first thought of. Much of the discussion in the paper is about these different elements - the matching adjustment, the volatility adjustment, the transitional arrangements - all designed to get us back to what we wanted in the first place, which is something that is less reactive to market conditions. But it is a hotchpotch.

There are four points I am keen to make, to encourage some discussion.

The first point is on the pros and cons of market consistency. I agree with almost everything in the paper. However, one point I have a slight divergence of opinion about is that it asserts that there may be flaws in following a dogmatic market consistent approach, but it is through market consistency that effective risk management is rewarded. I would not necessarily disagree but certainly, playing devil's advocate, if I spoke to UK pensions actuaries or a German life insurer, they would probably argue that forcing people to match liabilities with overpriced long-dated bonds is about as far away as you can get from effective risk management. Similarly, prioritising short-term mark-to-market and your ability to be solvent in 12 months' time rather than your ability to provide long-term returns is not effective risk management.

On the other hand, the opponents of market consistency do owe it to themselves to come up with something better.

Take the Churchill quotation that describes democracy, as "the worst form of government except all those other forms that have been tried from time to time" and change "government" to "regulation". Solvency II may be the worst form of regulation apart from all the other ones that we have considered.

Second, where is Solvency II too generous? Much of the industry debate has been about the areas where either the capital rule should be reduced or the governance of Solvency II should be made less burdensome. We are actuaries. We should be wearing our public interest hat here. Where do we think Solvency II should be strengthened, not just weakened?

The Working Party asked various questions at the Life Conference. We received an enthusiastic response to proposition A: capital requirements should be adapted to allow insurers to introduce management actions or allow for markets to find new levels.

If you look at the way the countercyclical regulations are applied in banks, perhaps it should be phrased more like B: "Capital requirements should be adapted to force insurers to set aside extra capital in benign market conditions, like today”. Would that have received such an enthusiastic response? Is that what we think? Should insurers be putting aside more money now, so they can release it later?

We should acknowledge self-inflicted wounds. When we had the debate back in the spring after the Treasury Select Committee enquiry and the profession's presentation, there was much debate on the 
use of swaps, for example, as a risk discounting tool, as if somehow that was imposed on us by some nasty people in Frankfurt.

However, if you look at history, the industry was the one arguing for swaps. The regulators preferred government bonds. Even when government bonds were used for everything else in Europe, we in the United Kingdom had a carve-out to be able to use swaps. So it was our idea in the first place.

Similarly, the risk margin seems to be one of the less beloved parts of Solvency II. Again, if you look back, it largely came from market consistent embedded value developments. If you look at the initial papers, the concept of this fixed cost of capital, which people do not seem to like, came from a paper from the Chief Financial Officers' Forum, as far as I can make out.

It is easy to blame other people but should we, as actuaries, at least admit that we perhaps failed to spot some of these things and be more honest in the debate? I do not mean that as a criticism of the paper, but it is an easy mistake to make.

Finally, the Working Party's focus was to test Solvency II against its objectives. They went back and looked at what those objectives were: improved consumer protection, harmonisation, effective risk management and financial stability. But how do you prioritise those objectives when they compete? Are they even all good things?

When the question was put to both the Working Party and the Life Conference, probably the biggest fail for Solvency II was providing harmonisation or consistency. Few people thought it had done that. Is that a bad thing? I think that is a good thing. If we have ten trillion of assets, which I think is what we have in the Eurozone under Solvency II, and all those companies are regulated in the same way, that seems like a recipe for a pro-cyclical, volatile market to me. The single market that Solvency II was designed to help facilitate existed well before Solvency II. I do not see much evidence of it happening post Solvency II, either. Maybe that was not even a desirable objective.

I would be interested in views on whether the objectives were the right ones. If we were starting again, would we start with that set of objectives?

The Chairman: I should like to introduce three members of the Working Party. The Chair is Dick Rae, who has been working with strategic asset allocation, asset liability and capital management implications of Solvency II since the first quantitative impact studies came out. For the last 3 years he has worked for BMO Global Asset Management, providing assurance solutions that are heavily influenced by Solvency II. Prior to that, he spent 15 years providing insurance solutions within investment banking. $\mathrm{He}$ is also the deputy chair of the Finance and Investment Board.

We also have Dylan Brooks. His current role is financial risk manager at the Phoenix Group. Prior to that, he spent his career at Prudential Plc and then Old Mutual Plc, being heavily involved in the implementation of Solvency II and the development of their risk management frameworks at those groups. Dylan has been actively involved in Solvency II policy development since 2007 through trade bodies and his role as chair of the Actuarial Association of Europe Solvency II Life Working Group. 
Finally, we have Andy Pelkiewicz. Andy is retired and lives in Germany after working in life insurance mostly in the United Kingdom but latterly in Germany as head of actuarial at Heidelberger Leben.

Mr A. J. Pelkiewicz, F.I.A.: I'll give a brief overview of the paper, and will then hand over to Dylan [Brooks], who will provide an update of developments since the paper was written. Our Chair, Dick Rae, will respond after the discussion.

Since early last year, our Working Party has been carrying out a review of Solvency II, to answer the question "Has it met its objectives?" in relation to life insurance. Within the Working Party, we have experience in consultancy, asset management, investment banking and life insurance; and a German, Irish and UK perspective.

We have assessed Solvency II against its original objectives, which include improved consumer protection, effective risk management, harmonisation and financial stability. For the purposes of this paper, we took the objectives as given, but Paul [Fulcher] has rightly questioned their relevance. We chose not to take deep dives on specific issues. There are other working parties doing that.

Back in January 2016, we held meetings to kick off our thinking, and then later in the year we sought views at the Life Conference. These discussions and surveys helped inform the paper.

Section 2 of the paper is about market consistency. Is market consistency a desirable end in itself or merely a useful tool to ensure a consistent approach to valuation? It is fair to say that the Working Party is not fully in agreement on this question.

In his opening, Paul [Fulcher] added to the debate with the help of Winston Churchill.

Solvency II started off with the intention of being market consistent. Later in its development, changes were needed to make it acceptable to member states in the new economic environment. As Paul has stated, these changes have departed from market consistency.

We look at some of the departures; in particular, the Ultimate Forward Rate and the Matching and Volatility Adjustments. We review the risk margin, which has been criticised as being too sensitive to interest rate movements, and also too large and too difficult to determine.

A further problem is that under the Standard Formula, hedging interest rate risk in the risk margin can increase the SCR (Solvency Capital Requirement). It is a real issue for UK annuity rates, with adverse pricing consequences. The Prudential Regulation Authority (PRA) has acknowledged these unfortunate consequences and EIOPA will consult on changes later in the year. In our paper, we present several of our and other commentators' ideas for changes to the risk margin. These could be of relevance to either the EIOPA review or a post-Brexit UK review. A new working party has been formed to address issues relating to the risk margin.

This section also covers transitional measures. Of particular interest is the Transitional Measure on Technical Provisions, which is widely used throughout Europe to phase in much of the impact of Pillar 1. 
In section 3, we assess capital requirements. We describe the Standard Formula and its many peculiarities, and suggest a few improvements.

This section also covers internal models. We see them as mainly positive, though we have listed several criticisms, including the approval process.

Section 4 covers the impact of Solvency II on behaviour, starting with ALM. Solvency II has certainly changed ALM practice throughout Europe. The regime now generally rewards the matching of assets and liabilities.

For UK annuities, the Matching Adjustment has had a huge impact on ALM. There has been a shift from gilts and corporate bonds to high-quality illiquid assets. This brings positive economic outcomes, with greater investment in areas such as infrastructure. However, some of the eligibility rules are too tightly drawn, adding to complexity.

In some countries, such as Germany, there is a trend to extend the duration of assets, to reduce interest rate risk.

The pro-cyclical nature of market consistency is of concern. As markets fall or become more volatile, insurers either have to find more capital or sell assets. This requires them to de-risk in the same timeframe as other institutions.

However, we know that markets can over-react, many are not deep and liquid, and life insurers often do not have immediate cash flows to pay.

A capital regime that provides time to respond would be desirable, and would bring Solvency II closer to meeting its objective of achieving financial stability.

This section also covers product design and consumer protection.

Moving on to section 5, we assess Pillar 2 and Pillar 3. We believe that Pillar 2 has been a major success of Solvency II. The Own Risk and Solvency Assessment (ORSA) has similarities to the previous Individual Capital Assessment (ICA) regime. However, Solvency II has raised the bar considerably. Although onerous, the ORSA should embed a strong risk management culture.

This section also looks at liquidity. Unusually, Solvency II is principles-based here. We believe this is appropriate for life insurers.

We explore Pillar 3, which has introduced greater consistency, detail and transparency into reporting and public disclosure across Europe. It is now far easier to obtain a high-level understanding of an insurer's balance sheet and corporate structure.

On the other hand, in the United Kingdom, Pillar 3 has meant a loss of some of the useful detail in the PRA returns, for example, within a company's various sub-funds. We also think that parts of the detailed reporting do not justify their costs and question the value of some of the areas where detailed reporting is required, particularly asset look-through data. 
Section 6 looks at harmonisation. The introduction of detailed regulations across Europe should have resulted in a high degree of harmonisation, but there are areas where this has not been achieved. These include discretion, gold-plating and interpretation of the regulations.

Finally, section 7 looks at Brexit, which Dylan [Brooks] will cover shortly.

To summarise our views, Solvency II is an impressive regulatory regime that provides a wide-ranging standardised framework across Europe. However, when you look at some of the outcomes, it falls well short of what it sought to achieve.

This may seem a harsh judgement, but the insurance industry has invested huge sums of money in implementation, and it is only right that a critical appraisal takes place.

We have highlighted many of the issues, and suggested areas where more work could be carried out.

I hope my "whistle stop" tour of the paper has given you a good overview. And now I will hand over to Dylan Brooks.

Mr D. Brooks, F.I.A.: I first started work on Solvency II in 2007 at Prudential when EIOPA was conducting its early Quantitative Impact Studies. I found it quite ironic that after UK insurers had spent so long preparing for Solvency II, and it finally went live last year, the UK public voted to leave the European Union (EU).

I am going to talk about some of the developments that have taken place since our Working Party first published its paper in May 2017.

The Treasury Select Committee Enquiry was launched in September 2016. The objectives included an assessment of the impact of Solvency II on the UK insurance sector, and to consider the options we have in the light of UK's decision to leave the EU. Naturally, the Working Party took a great deal of interest in this enquiry. The enquiry was closed in May due to parliament being dissolved for the general election. Consequently, the Treasury Select Committee did not conclude its work or publish a report for Parliament.

In July 2017, Nicky Morgan was elected by Parliament as the new Chair of the Treasury Select Committee to replace Andrew Tyrie. At this stage the committee has not opened a fresh inquiry into Solvency II. While the previous inquiry cannot be re-opened, the committee can open a new inquiry on Solvency II and refer to the evidence gathered in previous parliaments.

During the enquiry, the committee gathered 46 written submissions from industry stakeholders and conducted three oral evidence panels with delegates from the regulator, industry and members of the actuarial profession. We are pleased to have Andrew Chamberlain here today, who represented the profession on one of those panels.

Many of the issues raised by industry stakeholders in submissions to the committee were similar to topics that we discussed in our Working Party over the past year.

The profession's invitation to provide oral evidence was a good example of how policymakers and government value the independent learned opinions of the actuarial profession. Our Working Party 
welcomed the opportunity to provide some input into the profession's written submission. As outlined in our paper, the Working Party agrees with the profession's response in that a "revision to the current structure" of Solvency II in the United Kingdom would be preferable to a "root and branch replacement".

Although the inquiry has now been closed, the work of the inquiry has not been totally wasted. During the inquiry, the Association of British Insurers (ABI) wrote a letter identifying 23 concerns and issues with Solvency II. The PRA responded in writing earlier this year, explaining that they were "open to reform" on five of the 23 concerns raised by ABI, namely internal model change process, transitional recalculations, longevity risk transfer, external audits and legal entity identifiers. We understand that since then the PRA and industry have established joint working groups to develop proposals for reforms on these issues by the end of 2017 .

Clearly, we cannot talk about Solvency II today without mentioning Brexit. With the negotiations still ongoing, UK insurers are faced with great uncertainty over what the UK solvency regime might look like going forward, and what degree of access they will have to the EU market.

The Working Party sees both opportunities and threats arising from Brexit. There is an opportunity for the United Kingdom to adapt Solvency II to better meet its needs. There is a threat that the United Kingdom may still be bound by Solvency II rules in order to achieve passporting and equivalence, but with diminished ability to influence those rules in Europe.

In July 2017, the new Chair of the Treasury Select Committee wrote to the Bank of England requesting a briefing on UK insurers' preparedness for Brexit, and their contingency plans. The Bank of England responded, confirming that it is in the process of reviewing the risks, after receiving contingency plans from some 254 insurers and 147 banks. The Bank is anticipated to reach its conclusions this autumn.

We note from the Bank of England letter that the volume of Part VII transfers and authorisations in response to Brexit could increase sharply, causing costs and strains on the regulator.

EIOPA has also recently issued an opinion on supervisory convergence in the light of Brexit. The EIOPA advice appears to encourage EU member state regulators not to "fast track" UK firms which are seeking relocation in the run-up to Brexit.

More widely, EIOPA has been busy reviewing specific items of the Solvency II Delegated Regulation in order to respond to the European Commission's "call for advice" as part of its wider review of Solvency II.

EIOPA's advice will be staged in two phases, with the first set of advice being issued in October 2017 and the second set in February 2018. EIOPA has already issued a draft of its first set of advice to industry for consultation in July. The first set of advice covers aspects of design of the Solvency II Standard Formula, and there are a wide range of topics covered, including simplifications, external credit ratings and the loss absorbing capacity of deferred tax.

Across the EU, Solvency II will continue to evolve over time through the review mechanisms built into the Directive. The latest EIOPA consultations are evidence of that process. 
Regardless of the political landscape, the United Kingdom still needs to comply with Solvency II for the time being and embedding of Solvency II has continued over the year.

In July 2017, PRA published SS3/17 which formally sets out its expectations of firms that invest in illiquid assets within their Matching Adjustment portfolios, including equity release mortgages. This statement reiterates the high bar that the regulator has set for the risk management of illiquid assets. The Working Party viewed the trend towards insurers investing in illiquid assets as positive but noted that this has come at a cost of increased complexity of regulations.

During the first part of the year, we have seen the first wave of Pillar 3 disclosures by UK firms. The published Solvency and Financial Condition Reports of firms provided a wealth of granular data and information for the market to digest and we are keen to see how the investor community will react to these disclosures and use them going forward.

The Working Party felt that Pillar 3 reporting had been positive in the sense that it would encourage harmonisation across Europe. However, there were challenges and concerns raised around the costs and complexity, as Andy [ Pelkiewicz] alluded to earlier.

I am now pleased to hand this session over for comment and we encourage all of you who have been involved with Solvency II to share your views and experiences.

The Chairman: The discussion is now open to the floor. With that I would like to ask for the first contribution, please.

Mr J. Instance, F.I.A.: I want to speak as a Non-Executive Director of a small friendly society.

First, I should like to echo the chairman's comment that Solvency II has been useful in terms of policyholder protection, in that boards of those types of organisation are much more aware now of the risks that they are taking, and, to that extent, I think it enhances consumer protection.

The one big issue is the strain and stress on small organisations of such a major change. Despite all the hard work of the Working Party, what I would like to see is no change at all over the next five years or so. We lived with Solvency I for something like 30 years, or at least 25 years. There were some gradual changes, I suppose, primarily the change to the ICA regime, but it is about time that we thought about embedding Solvency II and start to think more about other issues, like what is good for the consumer, and the impact of technology on the way that our business is going to be run. Those are some big, strategic issues. We have not had the time to face up to them because of the stress of implementing Solvency II.

I agree with Paul [Fulcher]. We should just recognise that there is no such thing as a perfect regulatory regime. What we have is better than what we had before. There is no right answer. There is no right number for the amount of capital that an insurer needs. There is a lot of subjectivity and judgement involved. At least it is better than it was.

Frankly, I do not care about harmonisation. That is not just because our business is only in the United Kingdom. Europe is not harmonised in terms of the way it looks at customers. Germany is very different from the United Kingdom. Spain is very different in terms of the ways that customers 
think. That comes out from societal issues. In the United Kingdom, we are much more into equitybased savings and investments than other nations who prefer guarantees.

Tax, of course, has a major impact on the way that products are designed. Do we care that much about harmonisation?

My final plea is that regulators love to regulate. I used to be a regulator, so I understand that. It is their job to regulate.

We should discourage regulators from doing regulation. They must sit back and look at what they have done and manage it rather than say let us have another enquiry and think about how we can improve the regulation that we have.

Regulators will always find a reason to improve the regulations. Most people, so far as I can see, are targeting SCR ratios well above $150 \%$ - probably closer to $200 \%$. That is a big margin. That takes a lot of volatility. There is a big countercyclical adjustment in these benign times already in the way things are. I would be relatively relaxed at this stage and say let us not do any more.

Mr S. Findlay: I work at the ABI. In a different way I have been involved, as we all have, in pulling together messages from our members about the implementation of Solvency II and the future.

When I was reading through the paper, I was struck by how much consistency there is between the conclusions that you have reached and the views that we have gathered from our members. Of course, there is overlap between the memberships. But they are slightly different voices. When it comes to policyholder protection and risk management, there has been a marginal improvement, probably not worthy of the extraordinary cost and effort that there has been to get us there.

Pillar 2 is good practice and, in many ways, common sense. Meanwhile, Pillar 3 is excessive. It is difficult to see where the equivalent regulatory benefit comes from for all the costs of implementation of, and indeed the ongoing costs that firms are now incurring on, Pillar 3.

To echo the previous contribution, one of the messages that we have been trying to convey is that there is now a need for a period of calm to let this bed down and the desire to avoid a permanent state of change. At the same time, it is not perfect. We must be careful that we are not wanting to have our cake and eat it.

There are some things that we do not want to see changed but at the same time there are other things that are fundamentally flawed. I am thinking about the risk margin for one, which would be good to see reviewed.

I should like to end with a quick question. When I was looking through the results of the questionnaire, what struck me was that the question where views were the strongest, both from the Working Group and from the Life Conference, and both across average and median, was about gold-plating.

There was an overwhelming view that in the United Kingdom the PRA had gold-plated. One of the accompanying comments talks about how you are unable to find any evidence to substantiate that. I was wondering why you thought that was. Can that really be? 
Mr A. M. Slater, F.I.A.: Comments have been made that a lot of money has been spent on implementing Solvency II. Ultimately, that money is met by policyholders through increased premiums. There is talk that one of the objectives of Solvency II was to address failings in consumer protection. A lot of money has been spent; it must have been a big failing. Can somebody remind me what it was?

The Chairman: I had that as one of my questions too, although my question is slightly different. There is much documentation about costs of implementing Solvency II. I do not know how much of that is to do with Solvency II or whether it is just the new world environment in which we live where no one trusts a professional if he or she says, "I think it should be $4 \%$ ". I had to come up with an eight-page paper justifying what the inflation assumption was for my clients. Previously I had said, “ $3.5 \%$ sounds about right".

I do not know what people gain from the cost of internal models. A wise man said no one ever went bust from getting the equity stress wrong. They went bust because they did something stupid.

A member of the audience: What is going to be the impact of IFRS 17 on the Solvency II results? How can boards start reconciling the two sets of numbers?

Mr Instance: IFRS 17 is a good reason why we do not want to change Solvency II. There is a lot of work involved in certain organisations in restating their financial statements. I would say let us leave Solvency II alone.

I thought there was an interesting comment, "We thought we were gold-plating but so did everybody else". Every regulator in the market thought it had gold-plated. I suspect regulators have their own view about what the important issues are in their own markets.

Mr R. A. Rae, F.I.A.: It is harder to find something to write down in order that you can definitively say that gold-plating has taken place. There are anecdotally views to that effect. It is also fair to say regulators are there to regulate and they are going to have one view and the industry is going to have another view. The two are never going to marry.

In some areas, principally around the matching adjustment, a rigidity seems to have been introduced into the regime, which I do not think is necessarily helpful because, generally, rigidity increases risks. There are also inefficiencies around equity release mortgages, for example.

The matching adjustment was put into Solvency II for the benefit of the UK industry. It does not feel as though it has necessarily been viewed as generally as it could be in that respect.

Ms B. J. Illingworth, F.I.A.: I am not speaking on behalf of my employer here. My observation, having worked across different companies during the implementation of Solvency II, is that there is the potential for gold-plating to happen through the supervisor-led implementation. It is difficult to pinpoint evidence of it though.

For me, one of the difficulties of Solvency II is that companies have to report back to the supervisor what the supervisor tells them the answer should be in order to get their internal model approved. That leaves a weird world where to use your internal model you may be trying to interpret what you really think, what you should think as you have agreed with your supervisor and find a way forward. 
Mr W. M. Chishti, F.F.A.: Paul Fulcher made a good point about the risk margin and how it came from the cost-of-capital approach in the market-consistent embedded value. If you accept market consistency is the way forward, then the risk margin makes sense from a theoretical point of view, though you must compensate people for the non-hedgeable risk that they take on.

It is not necessarily a problem with the risk margin per se; the issue is with the rate at which the cost of capital is set, especially that it is unchanging in high or low interest rate environments.

If you can narrow that down to that being the nub of the issue with the risk margin, then it is to be hoped that in the profession somebody will be able to come up with a much better suggestion.

Mr Fulcher: May I comment on that? The point I was trying to make in the presentation is that I did go back to the Chief Financial Officer Forum papers from 2005 to 2006, and it clearly says that we think there should be a fixed cost of capital.

I was trying to make the point about self-inflicted wounds. It is easy to blame other people and the regulators but many of the problems with Solvency II were self-inflicted by people in this room, myself included.

The Chairman: The other thing is that, if you run a with-profits life book, you ask what the fuss is about the cost-of-capital risk margin, because it comes out at $1 \%$ and $2 \%$ of liabilities. At the most, without any loss absorbency, it is round about $10 \%$. I think it is being caused by the longevity stress and low interest rates more than anything else.

Mr Rae: It is clearly an annuity issue. It is an issue that affects the price of annuities for consumers. It is widely recognised that it is broken.

I take your point. I think that there is a good, solid argument for having a risk margin. Certainly, from my own personal perspective, when we used to do mergers and acquisitions deals, we used to look at the capital that was locked in. We used to apply a cost to it. We used to discount it an equity risk rate, not a risk-free risk rate. It is an area that needs further research.

Mr Pelkiewicz: If you go back to 2007, there were two options on the table. One was the cost of capital, which was the Swiss method. The other was the $75 \%$ value-at-risk model, which was the Australian method.

They are fundamentally different methods. Eventually, the European Commission chose the cost-ofcapital method, largely because it was easier to apply in practice. Despite all the difficulties of calculating a risk margin, that was one of the reasons why we have it.

There is a question whether we should have one at all. If so, why should we have it? Because they were considering two different methods, my personal view is that it was being seen - because everything has gone to best estimate and market consistency - as a general prudence margin.

It required some sort of intellectual justification and we have ended up with an unmanageable, hugely complicated, volatile beast, where maybe $25 \%$ of the SCR would do. It would be easier to calculate. 
The Chairman: I think the trouble with Solvency II is that it focusses boards too much on the rare occurrence, the 99 and a half percentile risks, whereas sometimes they need to be reminded about the business-as-usual type risks, the things that can happen every 3 or 4 years.

They need to work out management action plans not only for rare risks, but for what they will do if the stock market drops by $20 \%$ tomorrow, which is a fairly common occurrence, in my experience.

Ms N. S. Saunders: I work in general insurance, not in life insurance. I wanted to make some comments about gold-plating - specifically gold-plating that may or may not be happening by the PRA. This is my view, not necessarily my employer's view.

My view is that the PRA has gold-plated the requirements. It released a consultation paper not long ago about reducing some of the burden, as it put it, of the national-specific templates. It honestly felt like a token gesture.

It put in as many increases in the number of things they were asking for as decreases. I think the response from the $\mathrm{ABI}$ was also along those lines.

One of the other points is the requirement of internal model approved companies to meet the Standard Formula once a year. From their point of view, it is the only way of measuring model drift.

Could they not have thought about this in the many years leading up to Solvency II implementation: how they were going to measure model drift and how they are going monitor these models over time?

Instead, they are asking people to complete an onerous calculation, putting firms off even creating an internal model in the first place.

Mr J. M. Webber, F.I.A.: I work at Queen Mary University of London, which, thankfully, has not had to comply with Solvency II.

The question, “Did Solvency II meet its objectives?" is arguably the wrong question. Like every project, Solvency II kicked off with many objectives that were probably collectively unachievable. When you have a life industry, so diverse and with different products across Europe, how can you possibly achieve harmonisation without breaking the industries that you are trying to regulate? It was never going to be achieved.

Also, when we say, "Has it achieved its objectives?” What do we compare it to? Do we compare it to a 2000 Solvency I regime, where we had never heard of Individual Capital Assessment Standards (ICAS)? Or do we compare it to a 2012 regime, where probably most life companies were effectively managed under ICAS. I think if you compare it with 2000 you would say that this is much better. I would say that relative to ICAS, where I think the regulations were written on little more than two sides of paper, we have something which is more robust, more stable and more sustainable, and that is all positive.

I would also say that the paper, as a whole, is largely written from a UK perspective. Probably relatively few people have a good understanding of how disparately Solvency I had been implemented across Europe. Solvency II has started to address this. 
Under Solvency II we have a framework that does allow regulators to make changes in future. I think that there is a recognition that the first stab at Solvency II is not necessarily the final stab, whereas I think in many countries the changes to Solvency I were post implementation minimal. The United Kingdom would probably have been the exception.

Finally, a different subject. If you ask for evidence of gold-plating, I have two examples. I would say there is a difference between what the industry says about the PRA and what the PRA says about itself. If you read most of the PRA publications and speeches about Solvency II, everything is fine - just about. If you listen to what the industry says, particularly anecdotally and from some of the comments coming from the ABI, it has been badly flawed. I would say, particularly on the life side, that there has been a breakdown in trust between the regulator and the regulated.

People tell me that this has never happened but I am sure the internal model is proposed by good professional people working in the first line, and has then been reviewed, challenged and quite possibly changed by people in the second line, and has probably then been kicked into touch and possibly amended again by an auditor or a third-party firm of experts, before going to the regulator and changed again. How many actuaries does it take to calibrate an internal model? That is an interesting question.

The Chairman: I have one question, which I should like to ask the Working Party. What one thing would you change to improve Solvency II in the interest of the policyholders?

Mr Webber: I would take out the internal model.

I was staggered when I read the questions and challenges raised in the paper. People complaining about cost and benefit. How many of the issues arose out of the internal model? Which customer benefits materially from the internal model?

Are the companies really going to use the internal model to better manage the risks in their business and get a better insight into the way their business performs? Or is their priority to reduce their capital requirements?

I would like to see incentives for good management of the business and good use of models. I would prefer to see the regulators determine the capital requirements independently. Internal models are ridiculously complicated.

Andy Haldane's 2012 paper "The dog and the frisbee" talks about complexity. He talks about regulation becoming complex. Much of that is about internal models. He says it requires a regulatory response grounded in simplicity not complexity. I think that that is one of the most powerful statements I have heard about Solvency II, even if the paper is not about Solvency II.

The Chairman: That is a pretty controversial statement. Is anyone going to speak up in favour of internal models or should we now assume that the profession generally thinks that they should be dumped?

Mr A. N. Hitchcox, F.I.A.: I am in favour of internal models; however, I am more in favour of capital models. I am sure there are many actuaries in the industry who are frustrated. They work for 
multi-national groups who had economic capital models for years and years, and along came Solvency II.

From our experience of it, there are two points I would like to make. We are part of a group that wants to have a Standard and Poor's strong Enterprise Risk Management rating. There is an excellent document by Standard and Poor's about how they grade your use of economic capital models. It is about 60 pages long. We felt frustrated when along came Solvency II with hundreds of pages about to implement an internal model.

The second point is that maintaining that documentation adds about $30 \%-50 \%$ to our capital modelling team's resource requirements. We think that the Standard and Poor's economic capital model document was much higher quality.

It is not gold-plating by the PRA. We feel the excessive detailed burden of internal model documentation is a cost. Does it get passed to policyholders? Does it reduce return on equity? We are not sure. But it is a burden, and it also slows down our responsiveness to running the business.

I am sure that there are many groups around the world who feel that their own internal capital modelling was perfectly adequate, and then there is this extra $50 \%$ cost burden purely driven by the Solvency II requirements.

The Chairman: Is that in connection with a life company or a non-life company?

Mr Hitchcox: A non-life company; part of a group, though, that has life and non-life interests and must work across both.

The Chairman: Is anyone else going to speak up on behalf of internal models? So far, we have had slightly negative views of internal models and their usefulness in terms of Solvency II, although they are useful for boards and risk management.

A member of the audience: It is worth commenting that, in many cases, internal models produce a higher capital requirement than the Standard Formula simply because they are addressing limitations with the Standard Formula. Equity volatility risk, for example, is not reflected in the Standard Formula.

It is not always bad for policyholders for a firm to have an internal model. In some cases, the regulator is encouraging firms to use an internal model because it knows the deficiencies in the Standard Formula.

Ms Illingworth: I am not sure that higher capital does protect policyholders. If you make products uneconomic because of their capital cost, then you are not achieving your aim for Solvency II. You are not protecting your policyholders, and you are not protecting the longer term.

Mr Findlay: I agree with that. The subtle change in the question was an important one. If the question is about policyholder protection, then we get into a never-ending ratcheting of capital requirements and regulation in general. Of course, when you look at the regulators' statutory objectives, that is the objective that steers them. But when you think about policyholder impact more broadly, that is a far more interesting question. Where do we want to strike the balance? How do we 
avoid ending up with the financial stability of the graveyard? We will certainly have stability if we have no policyholders and no insurance companies.

The Chairman: And no one buying any policies at all.

Mr Findlay: Yes, and we do not have available and affordable insurance with all the societal benefit that goes along with it.

Mr Chishti: On the point on the internal model, think back to the immediate aftermath of the financial crisis, and the anger that the general public had against bankers and financial services in general. Trying to explain to the policyholder that the regulation allows a company to calculate its own capital, to use its own model to work out how much capital it needs to hold, can be difficult.

You can see why that is a good point about getting rid of the internal model. However, the internal model can still be useful in Pillar 2. In Pillar 1 you can make the case that everyone must use the same standard formula. Investors can allow for the weaknesses in it. In Pillar 2, where you have your ORSA, you can make that into a model as sophisticated as you want without the regulator interfering on how you should do things. Maybe the place for the internal model is in Pillar 2.

The Chairman: I think that deficiencies in the Standard Formula should be dealt with by changing the Standard Formula. If you are missing some risk, you should allow for it by changing the Standard Formula.

The other thing I wanted to mention briefly on the Standard Formula is that it seems a little odd that there is no volatility risk on the life insurance side and there is very little trend risk on the general insurance side. That, I think, is a failure of the standard model.

Mr Brooks: I should like to respond to your earlier question to the Working Party members: is there anything we would like to change? I do not speak on behalf of the other members in this respect, but I would change the cost aspect and the streamlining of the application procedures.

In the paper we quote the figure, which we got from the ABI. About $£ 3$ billion has been spent on implementing Solvency II in the United Kingdom to date. It cannot be wholly in the interests of customers to spend that much on implementing it.

I saw the complexity of the applications that we had to submit on an ongoing basis to amend the Matching Adjustment, to change our internal model.

It does strike me as somewhat over-engineered. I wonder if, going forward, there can be some ways of streamlining these processes. I am not sure how we will get that $£ 3$ billion back.

The Chairman: Through better risk management, obviously. I will now ask Dick Rae to respond on behalf of the Working Party.

Mr Rae: Fortunately, I have been able to respond along the way on some points. I will pick up Paul [Fulcher]'s comment about the objectives being, to an extent, at odds with each other. 
One that was mentioned was that financial stability would be at odds with market consistency. The question is: can you mitigate some of those risks? Can you have a regime that reflects the long-term nature of liabilities and allows changes to market movements to be spread over time?

I agree entirely with what Dylan [Brooks] was saying about what you would change: a general relaxation around some of the complexity. I think as a working party we felt that the models were too complex.

The trouble is the actions of the industry; who tend to optimise to the set of rules that they have. This gives rise to unfortunate consequences if the measures of risk do not reflect the actual risk.

Otherwise, I would like to pick up on the actual cost of Solvency II, which, as you say, has been enormous. It is interesting, Solvency II almost feels like business as usual now. There is a need for stability.

Nobody wants to move to a different regime but there are probably, it is fair to say, one or two areas that are worth fixing.

The Chairman: I am going to introduce our closer, Andrew Chamberlain, who is the chief actuary of Just. He is also the chair of the profession's Life Board. I think that it is fair to say that he has seen regulation of insurance companies from both sides in his varied and distinguished career.

Mr Chamberlain (closing the discussion): I think that it is quite difficult to draw clear threads from tonight's discussion. It is widely ranged. But then Solvency II is a wide subject. We have had a lot of discussion on gold-plating, the costs of the implementation, and the complexity both of internal models and of the regime itself. There have been quite a few comments about the bureaucratic nature, a lot of the surrounding materials, the volume and the sheer effort involved in doing anything in the Solvency II regime.

One does have to question whether, in the UK context, it has raised the bar or whether it is just something that was developing anyway.

Does Solvency II, particularly in the Pillar 2 ORSA regime, really require anything that the old the GENPRU did not? I would question whether it does, because GENPRU did require many of those things to be in place.

The impact of the risk margin obviously raised its head. What is the purpose of the risk margin?

How much security do policyholders wish to have, given that they end up paying for it? The Bank of England used to hold lots of gold in its vaults. It was the equivalent of Fort Knox for the United Kingdom, though on a much smaller scale. Until a few decades ago, they used to have a platoon of foot guards taken to the Bank of England. They used to stand guard over the gold all night, every night. That was stopped because it was too expensive.

That is a useful analogy. Is the risk margin too expensive to prospective policyholders? I think that is a question that needs to be answered. 
I think the comment that Dick [Rae] made about the discount rate is an important one. It is probably the risk-free discount rate that makes the risk margin so penal in effect.

The internal model was then discussed towards the end, perhaps prompted largely by Jim Webber's contribution. Barbara Illingworth, earlier in the discussion, had answered the point that he made about how many actuaries does it need to calibrate an internal model. The answer seems to be one, and that is the one who works for the supervisor.

We do have to question whether the industry has any internal models at all or does it have PRA models that are used internally? If that is the case, have we really added value to the process for the $£ 3$ billion, or whatever it is that it has cost the economy or the policyholder? If you measure it in the economy, it is probably all added to Gross Domestic Product, which would be a good thing, but I somehow doubt that there is a good return on it.

The Chairman: It just remains for me to express thanks to the authors, opener and closer and all those who participated in this evening's discussion. 